\title{
Editorial
}

\section{Describing the Undiscovered}

Over 1.7 million species have been described; approximately one million (60\%) of these species are insects (Roskov et al. 2018). That's remarkable diversity (and an impressive amount of work completed by insect taxonomists!). But again, these numbers represent only the described species. As we know, there are many, many more species awaiting description. When considering all species on earth, some of the most recent estimates indicate that there could be somewhere between 8.7 million (Mora et al. 2011) or even up to 6 BILLION species, if symbionts and cryptic species are considered (Larsen et al. 2017). When considering insect richness alone, estimates indicate that approximately 6 million species exist (e.g. Basset et al. 2012, Stork et al. 2015). If we narrow down our scope further, and just consider the Chironomidae, we have not yet described half of the projected 15,000 species (Armitage et al. 1995) that exist worldwide. No matter how you look at it, there are an incredible number of organisms that we know virtually nothing about.

I regularly share these statistics with students in my Biodiversity courses, emphasizing that we have barely scratched the surface in terms of what we know about life on Earth. To emphasize the point, I share my story of a short series of sampling sessions in four Minnesota, USA streams. For this particular study, I spent only perhaps 20-30 minutes in each stream, searching specifically for Micropsectra larvae and ignoring the rest of the stream biota. I walked away with three new species (Anderson et al. 2013). Many of you have similar stories, and ones that are even more impressive than mine. But, I find that stories like this always hook my students, prompting many good questions for discussion, such as: How many new species might I have found if I did a comprehensive analysis of these streams? What if a stream in a more diverse ecosystem had been studied? And the kicker: Why has no one discovered these species yet? In a world where taxonomy and systematics has taken a backseat in recent decades, we need to spend more time convincing people of the importance of our work. Why do we do what we do, and why should others care?

With climate change predictions looming in front of us, and species extinctions on the rise, how will the world look without these species? What cascading consequences lurk if there are mass extinctions caused by rising temperatures, habitat changes and loss, competition with invasive species etc., etc.? How will these changes impact interactions with other species? And thinking again about the millions of undescribed species - how many of them will we simply never get the chance to learn about?

Like many of you, I believe it is essential to learn all we can about this diversity and how certain species impact others via competition, predation/parasitism, mutualistic relationships, and so on, and also how the actions of our species might impact global diversity. Equally important is sharing these stories with the broader community and relaying the importance of understanding the diversity of life and what could happen if our actions (or inactions) result in loss of species.

This edition of CHIRONOMUS highlights what our relatively small community is doing to address some of these previously unknown questions. From descriptions of new species (Mouybayed-Breil and Ashe, 2018), new records of genera (Hamerlik and da Silva 2018), previously unknown life stages (Egan and Langton 2018) and species range updates (Namayandeh and Beresford 2018) to notes on the unique oviposition behavior of a midge that parasitizes unionid mussels, there are clearly new and important findings to share. We hope you enjoy learning of these discoveries, and continue to relay the importance of your own findings, not only with us and other colleagues in the scientific community, but with the broader community as well.

Alyssa M. Anderson

Department of Biology, Southwest Minnesota State University, Marshall, Minnesota, USA. E-mail: alyssa. anderson@smsu.edu

\section{References}

Anderson, A.M., Stur, E. and Ekrem, T. 2013. Molecular and morphological methods reveal cryptic diversity and three new species of Nearctic Micropsectra (Diptera: Chironomidae). - Freshwater Science 32:892-921. DOI: https://doi.org/10.1899/12-026.1 
Armitage, P.D., Cranston, P.S. and Pinder, L.C.V. 1995. The Chironomidae: Biology and ecology of nonbiting midges. Chapman \& Hall, $572 \mathrm{p}$.

Basset Y., Cizek, L. Cuenoud, P. et al. 2012. Arthropod diversity in a tropical forest. - Science 338:14821484. DOI: https://doi.org/10.1126/science.1226727

Egan, A.T. and Langton, P.H. 2018. Descriptions of four Nearctic Procladius Skuse pupal exuviae. - CHIRONOMUS Journal of Chironomidae Research 31: 30-36. DOI: https://doi.org/10.5324/cjcr.v0i31.2865

Funk, D.H., Roberts, S., and Graham, A. 2018. Oviposition behavior and host records for the parasitic midge Trichochilus lacteipennis (Johannsen) (Chironomidae: Orthocladiinae). - CHIRONOMUS Journal of Chironomidae Research 31:4-15. DOI: https://doi.org/10.5324/cjcr.v0i31.2436

Larsen, B.B, Miller, E.C., Rhodes, M.K. and Wiens, J.J. 2017. An inordinate fondness multiplied and redistributed: the number of species on Earth and the new pie of life. - The Quarterly Review of Biology 92: 229-265. DOI: https://doi.org/10.1086/693564

Hamerlik, L. and da Silva, F.L. 2018. First record of the genus Heterotrissocladius (Chironomidae: Orthocladiinae) from the Neotropical region. - CHIRONOMUS Journal of Chironomidae Research 31:43-46. DOI: https://doi.org/10.5324/cjcr.v0i31.2601

Mora, C., Tittensor, D.P. Adl S., Simpson, A.G.B., and Worm, B. 2011. How many species are there on Earth and in the ocean? - PLoS Biology 9:e1001127. DOI: https://doi.org/10.1371/journal.pbio.1001127

Moubayed-Breil, J. and Ashe, P. Cricotopus (s. str.) latellai sp. n., a new rheophilic species of the tremulusgroup from the Italian and French Maritime Alps (Diptera: Chironomidae). - CHIRONOMUS Journal of Chironomidae Research 31:4-15. DOI: https://doi.org/10.5324/cjer.v0i31.2498

Namayandeh, A. and Beresford, D.V. 2018. A new species in Rheocricotopus (R.) effusus group from Canada with review of Nearctic species of Rheocricotopus and Parametriocnemus (Chironomidae: Orthocladiinae). - CHIRONOMUS Journal of Chironomidae Research. 31: 16-29: 16-29. https://doi. org/10.5324/cjer.v0i31.2531

Roskov, Y. Wer, G. Orrell, T., Nicolson D., Bailly N., Kirk P.M., Bourgoin T., DeWalt R.E., Decock W., Nieukerken E. van, Zarucchi J., Penev L., eds. 2018. Species 2000 and ITIS Catalogue of Life, 29th November 2018. Leiden, the Netherlands. Available at: www.catalogueoflife.org/col.

Stork, N.E., McBroom, J. Gely, C., Hamilton, A.J. 2015. New approaches narrow global species estimates for beetles, insects, and terrestrial arthropods. - Proceedings of the National Academy of Sciences of the United States of America. 112:7519-7523. DOI: https://doi.org/10.1073/pnas.1502408112 